\title{
Leisure activities and retirement: do structures of inequality change in old age?
}

\author{
SIMONE SCHERGER*, JAMES NAZROO $†$ and PAUL HIGGS\$
}

\begin{abstract}
In this paper, relationships between old age, retirement and social inequalities, as marked by participation in leisure activities, are examined. Two issues are tackled: first, whether old age and particularly the transition into retirement have an effect on participation in three selected activities; and second, whether the social inequalities underlying these activities change with older age and retirement. The empirical investigation uses data from the first two waves of the English Longitudinal Study of Ageing (ELSA), which included variables on having a hobby, being a member of a club, and an index of participation in cultural events (cinema, theatre/opera/classical music performances, museums and galleries). The different socio-economic backgrounds of different age groups explain a considerable part of the observed age differences in these activities. Longitudinal analyses show that respondents tended to continue their activities regardless of changes in work and age, with two exceptions, namely that retirement was positively related to having a hobby, and those who stopped working because of an illness experienced a significant decline in all three of the examined categories of activity. The pattern of continuity also applied to socio-economic differences in patterns of participation in leisure activities. Some indications of slightly growing inequalities with age require further investigation.
\end{abstract}

KEY WORDS - old age, retirement, social inequality, class, leisure activities, participation.

\section{Old age, retirement and social inequality}

One of the most noticeable features of the second half of the 2oth century was the growth in the numbers and proportions of people in retirement, a period of the lifecourse that has often been seen as the site of significant inequality. Much of the work done on inequalities has focused on the differences between the retired and those of working age. Given that

* Centre for Social Policy Research, University of Bremen, Germany.

$\dagger$ The Cathie Marsh Centre for Census and Survey Research and Department of Sociology (School of Social Sciences), University of Manchester, Manchester, UK.

* Division of Research Strategy, University College London, London, UK. 
conventional approaches to social differentiation have linked individual positions in the employment system with occupational class, income and status, studying inequalities within the retired population has been more problematic. Retirees have, as a consequence, often been neglected in analyses of social inequality, or if included have been assigned to a residual class. This to some degree reflects the marginal social position of retirees. This article analyses the effect of retirement on leisure activities to test how the nature of class, as marked by this outcome, persists beyond working life.

It has been customary in some areas of the social sciences to treat retirement as little more than the 'rest' of life, so that it does not figure as a life stage of its own right but only as an appendix to working life. This applies to both British structured dependency approaches, which have generally considered this period of the lifecourse in terms of structurally enforced poverty experienced by the older person (Phillipson 1982, I998; Townsend I981, 2006; Walker I980), ${ }^{1}$ and to United States' approaches that have been less interested in inequality but retained a notion of later life as ultimately a period of decline, ill-health and exclusion - for example disengagement theory (Cumming and Henry i96r). Although contrasting concepts such as activity theory (Havighurst 1957; Havighurst, Neugarten and Tobin ig68; Havighurst et al. 1969) and continuity theory (Atchley I989) took issue with the inevitability of disengagement and emphasised the importance of continued engagement in social roles, they can be criticised for over-generalising the conditions of retirement.

Increasing affluence and improving health at older ages can be connected with the growing diversity of patterns of retirement and postretirement life, and have raised further doubts about whether structured dependency and disengagement approaches are adequate for describing the circumstances of current and future cohorts of older people (see Gilleard and Higgs 2000: 12-6). This has led to increased interest in the 'Third Age'. As popularised by Peter Laslett (1996/r989), this term refers to a period in the lifecourse that is relatively free from the constraints of life before retirement (specifically work and childcare obligations). Central to Laslett's concept is a stress on the agentic nature of later life and on retirement as giving opportunities actively to engage in new leisure and social activities ( $c f$. Weiss and Bass's (2002) related idea of 'productive ageing'). ${ }^{2}$ Even though the contemporary diversity of retirement experience makes the idea of a unifying (voluntary or involuntary) devaluation of older people through retirement unconvincing (even if there are still many impoverished retired people), the idea of agency without limits also seems inappropriate. The central question is not whether agency or structures shape life in old age. Instead, we should examine the circumstances under 
which the relation between structure and agency might change in old age - if it changes at all. To put the rather psychological approaches of activity theory and continuity theory in a sociological frame, we have to ask under which social conditions individual actors are facilitated to achieve an 'active' lifestyle and to sustain their activities, relationships and self-esteem in old age. This requires a focus on the relation between structures of social inequality and age, and especially on social structures and the transition into retirement, and how this relationship might shape activities post-retirement.

This paper contributes to such discussions of age and inequality by investigating three examples of social and leisure activities and their distribution among older people: cultural activities (going to the cinema, theatre/opera/classical music performances, visiting museums and galleries), having a hobby, and club membership (including work on committees). ${ }^{3}$ Before moving to the empirical inquiry, the next section of the paper discusses the general relationships between leisure and other activities and retirement, age and class.

\section{Inequality and activities in post-working life}

In general, three relationships between the structures of inequality and the transition into post-working life can be conceived (see Kohli i99o; Kohli et al. 1999). First, continuity of the individual's social position into post-working life is plausible, because the main economic (and also social and symbolic) resources in retirement reflect those available in working life, or are closely linked to the latter. Wealth and income post-retirement reflect how far a person has been able to accumulate wealth and pension entitlements during their working life. People with higher incomes are more likely to invest in private pensions, whereas those with lower incomes or incomplete working histories (both being more likely for women and members of ethnic minority groups) are more likely to depend solely on the basic state pension (Bardasi, Jenkins and Rigg 2000; Crown 200I: 354; Ginn and Arber 199I). This applies to various degrees to all pension systems. ${ }^{4}$

Second, through several mechanisms, an amplification of social differences could occur. Life-course research has shown that one's socioeconomic position does not remain stable over the life-course. Resources that privileged retirees are able to accumulate over their life-course can produce greater inequalities in later life, as can the accumulated disadvantages of others. Health could also lead to increasing differences, if the health problems related to advanced age are less frequently 
encountered or more easily tackled by those in a better socio-economic position (Banks, Karlsen and Oldfield 2003: I22; Blane 2006; George 200I: 223; Marmot, Siegrist and Theorell 2006; O'Rand 200I). Third, the effects of differences in pre-retirement social position would be attenuated if the pension system brought about a collective devaluation of all retirees, as suggested by some interpretations of theories of structured dependency. Moreover, health could act as a kind of equaliser (over and above selection effects) with increasing age, when health problems begin to affect people from all socio-economic strata. There is some confirmatory evidence of this, but only for the very old (Herd 2006; House et al. 1992, 1994).

The actual underlying patterns are of course more complicated than these simple, unidirectional hypotheses. The focus of this paper is on a related outcome of a person's social position - the leisure activities of older people after retirement. Since the balance between leisure and work shifts in retirement, it could be argued that participation in leisure becomes a more important dimension of social participation, and that its unequal distribution is a vital component of social inequality in old age. When applying the approaches described above to patterns of participation in various activities in retirement, two related issues must be addressed: the direct effect of retirement on one's activities, and the potential shifts in the socio-economic structures underlying these outcomes.

During mid-life, educational, occupational and income status play key roles in shaping all sorts of cultural participation (see Bennett and Silva $2006 a$; Chan and Goldthorpe 2005, 2007a, 2007b). ${ }^{5}$ These influences are various and intricate. Most obviously, the availability of financial capital might limit the scope of activities in which one is able to engage. Other 'hard' influences include residential location, spatial mobility and time budgets (often closely connected to one's position in the lifecourse) - and these are often moderated by income and wealth. For those with the lowest income and assets, paying for an entrance fee or club membership, for example, is sometimes out of the question. Beyond a certain level of income and wealth, however, other forms of capital become more crucial, because cultural capital is a necessary prerequisite for being interested in, understanding and enjoying certain forms of culture. Education is an important creator of this kind of capital. The social habitus, connected to social origin, educational qualifications and occupational status, renders different forms of cultural participation more or less attractive - which is often denominated by 'taste' (Bennett and Silva 2006 b; Bennett et al. 2008).

As discussed above, the general economic position of retirees is closely connected to their pre-retirement position. The idea of continuity might 
also be applied to cultural capital and tastes, many of which are acquired early in life and pursued throughout the lifecourse. These are strong reasons for supporting the thesis that one's socio-economic position continues to exert an influence on post-retirement activities. Which circumstances in retirement are most likely to bring about changes? Retirees may have more time to pursue cultural activities and to try something new (Parker 1979: 336). Furthermore, retirees may compensate for the loss of their occupational role by engaging in other activities (Atchley 1989; Ferraro 2001: $324-5$ ). This is more likely if their new activities are similar to their former paid work and occupational roles, e.g. volunteering or committee work. Intensified social or cultural participation may serve as new markers of status, particularly for retirees who previously enjoyed a high occupational status and who, therefore, have the potential to be more deeply affected by the loss of status and identity associated with retirement (see Stebbins 2000). Such a pattern could lead to increasing inequality, so the relation between retirement and leisure is also influenced by the relation between work and leisure before retirement ( $c f$. Parker i971, I982). Because of the traditional gendered division of housework and paid employment, gender differences must also be considered in this context (Colley i985). Laslett's normative idea of a completely 'new' retirement identity, divorced from any relation to the labour market, implies an intensification or amplification of activities. Culture, especially its highbrow forms, plays an important role in Laslett's concept, as those in their third age will have to contribute significantly to the continuity of cultural institutions, and retirement should be of a 'cultural character' (Laslett 1996/1989: г82, 215-6).

Although the opposite view, that retirement from the labour market is a starting point of voluntary 'disengagement' from society and a 'natural' consequence of ageing, is generally rejected as (no longer) applicable, there might be circumstances which lead to lower participation. Retirement could bring about the loss of social capital, contacts and occasions that also facilitate leisure activities, and decreasing wellbeing and self-esteem could result in the partial withdrawal. However, depression as a direct consequence of retirement seems to affect only a small group of retirees for a short time (Ferraro 200I : 320; McGoldrick I989: 99-I00). Perhaps more important is that some groups suffer from a crucial reduction in income after retirement, because they did not have enough income to invest in private or occupational pensions, or could not do so for substantial periods of their working lives, as is the case for many older women. Not surprisingly, on the whole this type of retirement poverty is more frequently found among people who already had a lower probability of participation during their working lives. ${ }^{6}$ 
The empirical investigation reported in this paper focuses on two connected issues. First, whether engagement in leisure activities changes with retirement and age, even after taking into account declines in health and related factors. Here, the different socio-economic profile of the different age cohorts has to be taken into account (see Cutler and Hendricks i990: I72). Second, the paper examines whether social inequalities in leisure activities change after the transition into retirement. For both issues, we explore the importance of different dimensions of social inequality (education, occupational class, wealth) and the role of health. Educational attainment is often considered to be most influential in explaining the pattern of engagement in social and cultural activities, but occupational class and wealth must be included to obtain a more complete picture of social inequalities in activities. Particularly for the current cohorts of older people, among whom large numbers have no educational qualification, occupational class and levels of wealth may additionally discriminate. Furthermore, we control for the existence of a partner in the same household, because her or his presence is likely to shape both the wish to meet other people outside the household during social or cultural activities and the opportunities for social engagement without leaving the home. The results should answer the question whether it is useful to apply the usual categories of class to later life, or whether a different logic of social inequality operates after the transition into retirement.

\section{Methods}

We use data from the first two waves of the English Longitudinal Study of Ageing (ELSA). ELSA is a panel study of men and women who at baseline in 2002 were aged 50 or more years. The first wave in $2002-03$ sampled those living in households that had previously responded to the I998, I999 or 200 I Health Surveys for England (HSE), an annual, nationally-representative cross-sectional household survey. Wave 2 of ELSA was conducted in 2004-05. Wave I achieved an individual response rate of 67 per cent of those eligible from the HSE and the response rate at Wave 2 was 8I.5 per cent of those eligible from Wave I. Analyses were weighted for non-response bias at Wave I and attrition bias between Waves I and 2 (but all case numbers shown in the analysis are unweighted). Further details of the study are available at http://www.ifs.org. uk/elsa/publications.php (see Banks et al. 2006, 2008; Marmot et al. 2003).

All variables used here were part of a self-completion questionnaire that complemented the main interview. We explore the follwing items: cultural activities (going to the cinema, theatre/opera/classical music 
performances, visiting museums and galleries), having a hobby, and club membership (including work in committees). The selection of these activities was constrained by the ELSA variables but enabled coverage of diverse types of engagement that differ with respect to inequality and age. Having a hobby was not defined in the questionnaire. It can refer to many different activities that might be practised alone or with others, and at home or elsewhere. The other two activities, in contrast, are likely to involve social contacts outside the home. At the same time, while the connection of highbrow cultural activities to higher social status is obvious, this relationship is much less clear for having a hobby and club membership. Not being a member of any club or not having any hobby might therefore be a stronger indicator of social deprivation than the named cultural activities.

For cultural participation, an additive index was computed from the responses to three questions that asked how often the respondent went to the cinema, a concert, opera or theatre performances, and to museums or galleries. ${ }^{7}$ The responses were coded on a scale from I 'twice a month or more' to 6 'never'. For the index, the direction of the values has been reversed, with high values indicating more cultural participation. Cronbach's alpha of 0.78 indicated that the index is reliable. ${ }^{8}$ The item, 'I have a hobby or pastime', was in a list of eight activities and the respondent had to tick those that applied to him or her. For club membership, the question wording was, 'Are you a member of any of these organisations, clubs, or societies?', and it was followed by a list of nine different kinds of clubs, including 'other organisations, clubs or societies'. ${ }^{9}$ If the respondent answered in the affirmative, the next question was: 'Thinking about all the organisations, clubs or societies that you are a member of, how many committee meetings if any, do you attend in a year?' Unfortunately, 25 per cent (unweighted I,399 persons) of the club members did not answer this second question at all. Instead of excluding these cases as missing values, they have been set as 'passive' members who did not attend any meetings; in other words, we assumed that these persons did not answer the question because they did not go to any meeting and thought the question did not apply to them. If these cases had been excluded, the share of active club members would have been unrealistically high.

The data analysis included three steps, the first being to conduct a descriptive overview of the prevalence of the activities in the sample at Wave 2. Then in order to establish the multivariate relationships, partial proportional odds models (for ordinal outcomes) and logistic regression models (for bivariate outcomes) were used. Finally, based on the combination of information from ELSA Waves I and 2, changes over two years 
in engagement in these activities were analysed using binary and multinomial logistic regressions. All the multivariate models controlled for gender, age, subjective health, existence of a (married or cohabiting) partner living in the same household, highest educational qualification, occupational class using the National Statistics Socio-economic Classification (NS-SEC), and household wealth quintiles (non-pension household wealth). ${ }^{10}$ To aid comprehension, the measures of educational qualification and occupational class were summarised, after checking that the principal trend was the same as that for the disaggregated values. Also, because educational qualifications, occupational class and wealth were closely related, every model was checked for absence of multicollinearity.

In most of the presented analyses, age was entered as a non-linear categorical variable, but where there was a clear linear trend, the linear variable (age in years) was used. As a measure of health, general subjective health ('How is your health in general?' with a five category response) was used, because it is a simple yet differentiated measure. Analyses using other health measures, namely the existence of a long-standing illness and its possibly limiting character, and restrictions in the activities of daily living (ADL), had very similar results, regardless of which general health measure was examined. Although the general subjective health measure is ordinal, it was applied as a linear variable after the linearity of its influence had been verified.

Economic activity status was added to the models as an independent variable. For the cross-sectional models four categories were used: those who were in paid work and not retired (just under one-third of the sample); those who were not in work and described themselves as retired (around 50\%); those who neither worked nor were retired (around $14 \%$, two-thirds of whom were women looking after home or family, with the majority of the other third describing themselves as permanently ill or disabled, and a few as unemployed); and those who were in work but said that they were retired (less than $3 \%$, with more than half of them beyond state retirement age). A variable based on these four categories that indicated change in labour force participation was included in the longitudinal models.

\section{Results}

Of the ELSA sample, 6,768 answered questions on cultural participation. ${ }^{11}$ Altogether the distribution of responses to this question was skewed, so a summarised version of the index of cultural participation containing four groups was used. One-quarter of the respondents scored o points on the 
additive index of cultural participation; about 28 per cent had I- 3 points, and about one-third $4^{-7}$ points. Only about I3 per cent, with 8 or more points, belonged to the very active group. Turning to reports of having a hobby, 7,649 answered the question, approximately 70 per cent in the affirmative, and 7,232 responded to the question about being a club member or served on committees. Slightly more than one-quarter were not a member of a club, and about 40 per cent stated that they were a member but had not attended any committee meetings during the previous year, whereas one-third were members and attended committee meetings.

The descriptive analyses show that cultural participation decreased (nearly linearly) with increasing age. Having a hobby and being a club member was most frequent among the middle-aged, with the highest share of hobbyists in the late fifties and sixties, and the greatest number of passive and active club members in the age group $70+$ years. All three activities and their extent were closely connected to better health outcomes. While women participated rather more often in cultural activities than men, slightly more men had a hobby. Men were also more likely than women to be active club members and to attend committee meetings. There were no clear differences between those who lived with a partner and those who did not. On the whole, the latter group appeared to be slightly more active, particularly in cultural activities. Cultural participation, having a hobby and being a passive or active club member all correlated positively with educational qualification, household wealth and occupational class, although the starting levels of the activities differed. Around $4 \mathrm{O}^{-} 5^{\mathrm{O}}$ per cent in the lowest classes had a hobby or were a club member, but many more $(75 \%)$ never or very rarely went to the cinema, museums, galleries or theatre and concert performances $\left(\mathrm{o}^{-} 3\right.$ points on the additive index).

The cross-sectional models that we next discuss examined the relationship between these leisure activities and economic activity and age after taking into account differences in socio-economic position and health. Such adjustments are necessary, because in cross-sectional analyses, processes connected to the ageing of individuals are easily confounded with cohort effects. For example, educational background - which might apply especially to the 'highbrow' cultural field - varied markedly with age. For example, among the oldest age group (9o or more years), 67 per cent had no educational qualification, three times the 22 per cent share among the youngest age group $\left(5^{2-54}\right.$ years). Table I shows a partial proportional odds model with cultural participation as the dependent variable. ${ }^{12}$ The ordinal dependent variable is a four-category summary of the cultural participation index, the lowest category indicating the lowest 
T A B L E I. Cultural participation among those aged 50 or more years, England, 20O2-O4

\begin{tabular}{|c|c|c|c|}
\hline \multirow[b]{2}{*}{ Variables and categories } & \multicolumn{3}{|c|}{$\begin{array}{c}\text { Cultural participation at Wave } 2 \\
\text { (I/lowest, } 4 / \text { highest })\end{array}$} \\
\hline & $2,3,4$ versus $\mathrm{I}$ & 3,4 versus $\mathrm{I}, 2$ & 4 versus $\mathrm{I}, 2,3$ \\
\hline & \multicolumn{3}{|c|}{ Odds ratios of being in a higher category } \\
\hline \multicolumn{4}{|c|}{ 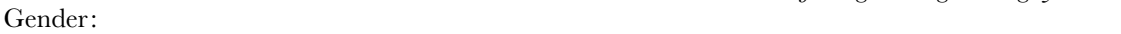 } \\
\hline Male & I.00 & I.OO & I.OO \\
\hline Female & г. $63^{* * *}$ & $\leftarrow$ & $\leftarrow$ \\
\hline Age in years & $0.96^{* * * *}$ & $\leftarrow$ & $\leftarrow$ \\
\hline Self-reported health problems & $0.70^{* * * *}$ & $0.80^{* * *}$ & $0.8 \mathrm{I}^{*}$ \\
\hline \multicolumn{4}{|l|}{ Partner: } \\
\hline Married or cohabiting & I.00 & I.00 & I.OO \\
\hline Not living with a partner & I.o6 & I. $47^{* * *}$ & $2.48^{* * *}$ \\
\hline \multicolumn{4}{|l|}{ Educational qualifications: } \\
\hline None & I.00 & I.OO & I.OO \\
\hline NVQI-3, CSE, GCE-O, GCE-A, foreign/others & $2.14^{* * *}$ & $2.40^{* * *}$ & 0.78 \\
\hline $\mathrm{NVQ}_{4-5}-$, degree, higher & $3 \cdot 4^{* * * *}$ & $4 \cdot 3^{6 * * *}$ & І.68 \\
\hline \multicolumn{4}{|l|}{ Occupational class (NS-SEG): } \\
\hline Routine and manual & I.00 & I.OO & I.OO \\
\hline Intermediate & I. $39 * * *$ & $\leftarrow$ & $\leftarrow$ \\
\hline Managerial or professional & I. $92^{* * * *}$ & $\leftarrow$ & $\leftarrow$ \\
\hline Household wealth (quintiles) & I. $3^{* * * *}$ & $\leftarrow$ & $\leftarrow$ \\
\hline \multicolumn{4}{|l|}{ Economic activity status: } \\
\hline Not retired, working & I.OO & I.OO & I.OO \\
\hline Not retired, not working & $0.75^{* *}$ & $\leftarrow$ & $\leftarrow$ \\
\hline Retired, working & I. $80^{* *}$ & I. 50 & $4.2 \mathrm{I}^{* * *}$ \\
\hline Retired, not working & I.IO & $\leftarrow$ & $\leftarrow$ \\
\hline
\end{tabular}

Notes: Wave I was in 2002-03, Wave 2 was in 2004. Partial proportional odds model for ordinal outcomes. Sample size 6,642. Pseudo $R^{2}=0.16$. $\leftarrow$ assumption of parallel regressions fulfilled, i.e. same coefficients for all contrasts. CSE: Certificate of Secondary Education. GCE-A: General Certificate of Education Advanced Level. GCE-O: GCE Ordinary Level. NS-SEG: Office of National Statistics Socio-economic Classification. NVQ: National Vocational Qualification.

Significance levels: $* p<0.05, * * p<0.01, * * * p<0.001$.

participation. An odds ratio above I.o indicates that the stipulated category of the independent variable increased the probability of being in a higher participation group, while an odds ratio below I.o indicates a heightened probability of being in a lower one. The variables with three different odds ratios for the three contrasts are those which violate the assumption of parallel regressions; the others simply have the same coefficient for all three contrasts (which are shown by the small arrows).

Many of the bivariate relations were also significant in the multivariate model. Women participated more than men, and a higher age had a negative influence on cultural participation. The same applied to

\section{CAmbridge JDURNALS}


subjective health. Respondents without a partner in the same household were more likely to be among the most active consumers of highbrow culture. With higher wealth, educational qualification and occupational class, participation was higher. Educational qualification in particular differentiated between low and medium participation. With the socioeconomic controls, the numerous groups of (a) working and not-retired people and (b) retired not-working people did not differ. Put another way, the lower socio-economic status of retirees and their worse health explained their lower participation, but this was not the case for the other two economic-activity status groups. The very few who were retired and still worked participated significantly more than others. In contrast, being not retired and not working lowered cultural participation significantly. Additional analyses that differentiated the last subgroup showed that the very negative effect applied only to those who were permanently ill or disabled. Neither those who were unemployed, nor those looking after the home or the family, showed a significant difference from those working and not retired (figures not shown).

Table 2 presents the logistic regression for having a hobby. Values above I.o indicate significantly heightened odds of having a hobby, and values between o and I.o indicate a lowered probability. In contrast to the results for cultural participation, both non-working and working retirees were more likely to have a hobby than non-retired and working people. Those who were neither retired nor working did not differ significantly. As there was a non-linear trend for age, age groups have been used in this analysis: the middle age groups (from 55 to 64 years) were more likely than the younger ones to have a hobby, but at very high ages this probability decreased significantly. As for cultural participation, higher education, wealth, occupational class and health all related positively to having a hobby, but there was no effect from living with a spouse or partner. Similar models for club membership (analysis not shown) show that the middle age groups were significantly more active, both with regard to club membership and attendance at committee meetings. Economic activity status had no significant influence. In spite of somewhat smaller coefficients than for cultural participation, all three dimensions of socio-economic position were again highly significant determinants, as was health. Not living with a partner increased the probability of engaging in clubs, but the effect was again smaller than for cultural participation.

Analysis of change over the first two waves of ELSA showed that the majority of respondents did not change their labour force participation status - 6o per cent remained out of work (most of them were retired) and just over 30 per cent remained in paid work. Those who stopped working 
T А в L E 2. Logistic regression of having a hobby at Wave 2

\begin{tabular}{|c|c|}
\hline Variables and categories & Odds ratio \\
\hline \multicolumn{2}{|l|}{ Gender: } \\
\hline Male & I.OO \\
\hline Female & 0.98 \\
\hline \multicolumn{2}{|l|}{ Age group (years): } \\
\hline $5^{2-54}$ & I.OO \\
\hline $55-59$ & I. $47^{* * *}$ \\
\hline $6 o-64$ & I. $3^{*}$ \\
\hline $65-69$ & I.I4 \\
\hline $70-74$ & I.OI \\
\hline 75-79 & 0.85 \\
\hline $80-84$ & $0.67^{* *}$ \\
\hline $85^{-89}$ & $0.5^{8 * *}$ \\
\hline $90+$ & $0.39^{* *}$ \\
\hline Degree of self-reported health problems & $0.74^{* * *}$ \\
\hline \multicolumn{2}{|l|}{ Partner: } \\
\hline Married or cohabiting & I.oo \\
\hline Not living with a partner & 0.98 \\
\hline \multicolumn{2}{|l|}{ Educational qualification: } \\
\hline No qualification & I.OO \\
\hline NVQI-3, CSE, GCE-O, GCE-A, foreign/others & I. $67^{* * * *}$ \\
\hline $\mathrm{NVQ}_{4-5}$, degree, higher & $2.74^{* * *}$ \\
\hline \multicolumn{2}{|l|}{ Occupational class (NS-SEG): } \\
\hline Routine and manual & I.OO \\
\hline Intermediate & $\mathrm{I} .07$ \\
\hline Managerial or professional & I. $19^{*}$ \\
\hline Household wealth (quintiles) & I.I $7^{* * * *}$ \\
\hline \multicolumn{2}{|l|}{ Economic activity status: } \\
\hline Not retired, working & I.0o \\
\hline Not retired, not working & I.I9 \\
\hline Retired, working & I. $76^{*}$ \\
\hline Retired, not working & I. $62 * * *$ \\
\hline
\end{tabular}

Notes: Sample size 7,505. Pseudo $R^{2}=0.09$. CSE: Certificate of Secondary Education. GCE-A: General Certificate of Education Advanced Level. GCE-O: GCE Ordinary Level. NS-SEC: Office of National Statistics Socio-economic Classification. NVQ: National Vocational Qualification.

Significance levels: $* p<0.05, * * p<0.01, * * * p<0.001$.

between the two waves can be divided into several subgroups using the self-descriptions of main activities and status: about 5.5 per cent retired between the two waves, 0.4 per cent became unemployed, 0.7 per cent became permanently sick or disabled, and o.8 per cent began to look after the home or family. About I.7 per cent of the respondents began working between Waves I and 2. Altogether, there were few changes in the respondents' cultural participation, hobbies and club membership over the two waves, except that there was a slight decrease in engagement in all three. It was only those that stopped working between Waves I and 2 and

\section{CAMBRIDGE JOURNALS}


T A в L E 3. Logistic regressions of changes in cultural participation between Wave I and Wave 2

\begin{tabular}{|c|c|c|}
\hline \multirow[b]{2}{*}{ Variables and categories } & \multicolumn{2}{|c|}{ Change of cultural participation } \\
\hline & $\begin{array}{l}\text { Model I: } \\
\text { Improvement }\end{array}$ & $\begin{array}{l}\text { Model 2: } \\
\text { Deterioration }\end{array}$ \\
\hline & \multicolumn{2}{|c|}{ Odds ratios } \\
\hline Cultural participation at $\mathrm{W}_{\mathrm{I}}$ (baseline) & $0.8 \mathrm{I} * * *$ & I. $49^{* * * *}$ \\
\hline $\begin{array}{l}\text { Gender: } \\
\text { Male } \\
\text { Female }\end{array}$ & I 0.96 & I $0.84^{*}$ \\
\hline Age in years & $0.98^{*}$ & I.OI* \\
\hline $\begin{array}{l}\text { Change in economic activity status } \mathrm{W}_{\mathrm{I}}-\mathrm{W}_{2} \text { : } \\
\text { Working at both waves } \\
\text { Not working at both waves } \\
\text { Not working to working } \\
\text { Working to retired } \\
\text { Working to unemployed } \\
\text { Working to sick/disabled } \\
\text { Working to looking after home }\end{array}$ & $\begin{array}{l}\text { I } \\
0.87 \\
0.55 \\
0.85 \\
\mathrm{I} .26 \\
{ }_{2}^{2} \\
0.83\end{array}$ & $\begin{array}{l}\text { I } \\
\text { I.08 } \\
0.53 \\
0.88 \\
0.99 \\
2.66^{*} \\
\text { I. } 24\end{array}$ \\
\hline $\begin{array}{l}\text { Degree of self-reported health problems at } \mathrm{W}_{\mathrm{I}} \\
\text { Change in self-reported health }\end{array}$ & $\begin{array}{l}0.76^{* * * *} \\
\mathrm{I} .23^{* * * *}\end{array}$ & $\begin{array}{l}\text { I. } 25^{* * * *} \\
0.8 \mathrm{I}^{* * *}\end{array}$ \\
\hline $\begin{array}{l}\text { Partner: } \\
\text { Married or cohabiting } \\
\text { Lives without a partner }\end{array}$ & I $53^{* * *}$ & $\begin{array}{l}\text { I } \\
0.88\end{array}$ \\
\hline Household wealth (quintiles) & I.03 & $0.86 * * *$ \\
\hline $\begin{array}{l}\text { Occupational class (NS-SEG): } \\
\text { Routine and manual } \\
\text { Intermediate } \\
\text { Managerial or professional }\end{array}$ & $\begin{array}{l}\text { I } \\
\text { I. } 26 \\
\text { I. } 6 \mathrm{I}^{* *}\end{array}$ & $\begin{array}{l}\text { I } \\
0.78 * \\
0.68 * *\end{array}$ \\
\hline $\begin{array}{l}\text { Educational qualifications: } \\
\text { None } \\
\text { NVQ }^{-}-3 \text {, CSE, GCE-O, GCE-A, foreign/others } \\
\text { NVQ }_{4}-5 \text {, degree, higher }\end{array}$ & $\begin{array}{l}\text { I } \\
\text { I. } 5 \mathrm{I}^{* *} \\
\text { I. } 56^{* *}\end{array}$ & $\begin{array}{l}\mathrm{I} \\
0.7 \mathrm{I}^{* * *} \\
0.39^{* * *}\end{array}$ \\
\hline
\end{tabular}

Notes: Sample sizes: 6,57I (Model I), 6,620 (Model 2). Pseudo $R^{2}=0.05$ (Model I); o.I6 (Model 2). I. For change by a single (ordinal) category during $\mathrm{W}_{\mathrm{I}}$ to $\mathrm{W}_{2}$. 2. Insufficient variance and predicts failure perfectly; dropped and 49 observations not used. CSE: Certificate of Secondary Education. GCE-A: General Certificate of Education Advanced Level. GCE-O: GCE Ordinary Level. NS-SEC: Office of National Statistics Socio-economic Classification. NVQ: National Vocational Qualification.

Significance levels: $* p<0.05, * * p<0.01, * * * p<0.001$.

became permanently sick and disabled who reported clear decreases in cultural participation, club activities and hobby pursuits.

In spite of the low frequencies of these changes, multivariate analyses can help to differentiate this picture. Perhaps the gains of the retired were offset by emerging health problems. The change in cultural participation between Waves I and 2 was captured by two logistic regression models of the probability of improving or lowering one's participation (Table 3).

\section{CAMBRIDGE JOURNALS}


Both models controlled for the level of cultural participation at Wave I. This was necessary because people with a higher starting point had more chance of decreasing their participation, whereas the participation of those with the lowest starting point could not drop (and vice versa for the increase). Values above r.o indicate a heightened probability of increased cultural participation (or in Model 2 of a decrease), and values between zero and I.o indicate a lowered probability in comparison to the reference group.

The first model identified the factors associated with rises in cultural participation of three or more points between the two waves, which applied to only 472 respondents ( $7 \%$ of the sample). Whereas wealth did not exert a significant influence on the probability of improving one's cultural participation, higher educational attainment and occupational class clearly did so. Furthermore, the respondents whose health had improved between the two waves also had a higher probability of improved cultural participation. Not being married or cohabiting also increased the likelihood of an improvement. The only change in economic activity status that exerted a significant influence was stopping work and becoming permanently ill or disabled in 2004, for which no coefficient could be computed because belonging to this group predicted 'failure' perfectly and the respective cases had to be excluded from the model. Put another way, among these 49 people, not one improved their cultural participation.

The second model identifies the factors associated with a decrease in cultural participation by three or more points, which affected 744 (II \%) of the respondents. Again, stopping work between the two waves and being permanently ill or disabled was the only category of economic-activity status transition that had a significant influence, with these respondents having a much higher probability of a decrease. Women, wealthier persons, those of higher educational attainment and members of higher occupational classes all had a significantly lowered probability of a decrease in cultural participation between the two waves. There was no significant effect for being married or cohabiting. So the change in cultural participation between 2002 and 2004 was dependent on other things as well as socio-economic position: the wealthier and better-educated respondents had a significantly higher probability of increasing their cultural participation, and a low probability of decreased participation.

A quite similar result can be seen for the two other fields of activities. With respect to giving up or taking up a new hobby, a multinomial logistic regression was computed. Table 4 gives the relative risks of having a hobby in both waves (column I), of taking up a hobby between the waves (column 2), and of giving up one's hobby (column 3), compared to those 
T А в L E 4. Multinomial logistic regression of change in having a hobby, Wave I to Wave 2

\begin{tabular}{|c|c|c|c|}
\hline Variables and categories & $\begin{array}{c}\text { Hobby both } \\
\text { waves }\end{array}$ & $\begin{array}{l}\text { Starts } \\
\text { hobby }\end{array}$ & $\begin{array}{l}\text { Stops } \\
\text { hobby }\end{array}$ \\
\hline Gender: & \multicolumn{3}{|c|}{ Relative risks } \\
\hline Male & I.OO & I.OO & I.OO \\
\hline Female & I.OI & 0.89 & I.06 \\
\hline \multicolumn{4}{|l|}{ Age group (years): } \\
\hline $5^{2-54}$ & I.OO & I.OO & I.OO \\
\hline $55^{-59}$ & I. $64^{* *}$ & I. 37 & 1.20 \\
\hline $60-64$ & I. $.8^{* * *}$ & I.I3 & I.23 \\
\hline $65-69$ & I. $46^{*}$ & 0.97 & 1.20 \\
\hline $70-74$ & I.37 & 0.94 & I. $3^{8}$ \\
\hline $75^{-79}$ & 0.98 & 0.76 & I.I 2 \\
\hline $80-84$ & 0.75 & 0.60 & I.o6 \\
\hline $85-89$ & $0.59^{*}$ & 0.80 & 0.97 \\
\hline $90+$ & $0.4 \mathrm{I}^{*}$ & 0.49 & I.03 \\
\hline \multicolumn{4}{|l|}{ Change in economic activity $\mathrm{W}_{\mathrm{I}}-\mathrm{W}_{2}$ : } \\
\hline Working both waves & I.OO & I.OO & I.OO \\
\hline Not working both waves & I. $59^{* * * *}$ & I. $72^{* *}$ & I.I7 \\
\hline Not working to working & I.OO & I. 38 & 0.63 \\
\hline Working to retired & I. $3 \mathrm{I}$ & I.9I* & 0.80 \\
\hline Working to unemployed & $0.9 \mathrm{I}$ & 0.74 & 0.82 \\
\hline Working to sick/disabled & I.03 & 0.32 & I. 72 \\
\hline Working to looking after home & I. 27 & 0.84 & I. 50 \\
\hline Degree of self-reported health problems at $\mathrm{W}_{\mathrm{I}}$ & $0.6 \mathrm{I} * * *$ & $0.80^{* *}$ & $0.80^{* * *}$ \\
\hline Change in self-reported health ${ }^{1}$ & $\mathrm{I} \cdot 3^{6 * * *}$ & I.I $6^{*}$ & I.05 \\
\hline \multicolumn{4}{|l|}{ Partner: } \\
\hline Married or cohabiting & I.OO & I.OO & I.OO \\
\hline Lives without a partner & 0.96 & I. I5 & 0.95 \\
\hline Household wealth (quintiles) & $\mathrm{I} .2 \mathrm{I}^{* * *}$ & I.IO & I.04 \\
\hline \multicolumn{4}{|l|}{ Occupational class (NS-SEG): } \\
\hline Routine and manual & I.OO & I.OO & I.OO \\
\hline Intermediate & I.I2 & I.II & I.07 \\
\hline Managerial or professional & I. $3^{8 * *}$ & 0.96 & $\mathrm{I} .22$ \\
\hline \multicolumn{4}{|l|}{ Educational qualification: } \\
\hline No qualification & I.OO & I.OO & I.OO \\
\hline NVQI-3, CSE, GCE-O, GCE-A, foreign/others & I. $89 * * *$ & $\mathrm{I} .27$ & I.I 6 \\
\hline $\mathrm{NVQ}_{4}-5$, degree, higher & $3.76^{* * * *}$ & $2.07^{* *}$ & I. $49^{*}$ \\
\hline
\end{tabular}

Notes: Sample size 7,206. Pseudo $R^{2}=0.07$. The reference case is no hobby at either wave. I. For change by a single (ordinal) category during $\mathrm{W}_{\mathrm{I}}$ to $\mathrm{W}_{2}$. CSE: Certificate of Secondary Education. GCE-A: General Certificate of Education Advanced Level. GCE-O: GCE Ordinary Level. NS-SEC: Office of National Statistics Socio-economic Classification. NVQ: National Vocational Qualification. Significance levels: $* p<0.05,{ }^{* *} p<0.01, * * * p<0.001$.

not having a hobby at both waves, the reference group. ${ }^{13}$ The part of the model for those who continued to pursue their hobbies shows that they were socio-economically privileged and had better health and better health development. Concerning age, the high relative frequency of 
having hobbies among the middle aged was confirmed, as were low frequencies among the very oldest.

More interesting are the groups that reported a change. Those taking up a hobby between waves constituted about 5 per cent of the sample and those who gave up their hobby were I 5 per cent. The small group of hobby 'newcomers' had fewer health problems than others or had even experienced improved health between the two waves. Not working at both waves, or having stopped working during the previous two years and being retired, increased the odds of starting a hobby. These odds were also increased for respondents of the highest educational class. Interestingly, the result for the hobby-quitters was not so different, for they too had fewer health problems in Wave I, and they were significantly better educated - which is not so surprising given that the reference group did not have a hobby at both waves. There was no effect of health change for this group. Worsening health was not related to giving up hobbies, and not being married or cohabiting did not influence the probability of starting, stopping or keeping a hobby.

The final multinomial logistic regression model is based upon a variable on club membership which has five categories: 'no membership', 'passive membership', 'active membership and I-4 committee meetings per year', 'active membership and $5^{-12}$ committee meetings per year' and 'active membership and more than I2 committee meetings per year'. Each increment of the scale was taken to represent more intense participation. Table 5 shows the relative risks of increasing and decreasing engagement in comparison with unchanged engagement. Age and work transitions were mostly insignificant in these models, with the only significant difference occurring for those who were not working at both waves (mainly retired people) - they were less likely to decrease their engagement than those who were working at both waves. ${ }^{14}$ Health problems at Wave I rendered an increase less likely and a decrease more likely, but only increased engagement was positively influenced by changes in health. Respondents living alone were not significantly different, although the coefficients indicate that they were more likely to increase their engagement. Finally, and in line with previous results, the highest occupational group were less likely to reduce their engagement and more likely to intensify it. Educational attainment produced similar effects, but mainly because higher education prevented a decrease rather than enhanced engagement.

More precise insights into age-related changes of the relation between social structure and leisure might be gained from analyses stratified by socio-economic groups. The sample sizes in the above exampleespecially in the labour-related change subgroups - were not sufficient for 
T A B L E 5. Multinomial logistic regression of change in engagement in clubs, Wave I to Wave 2

\begin{tabular}{|c|c|c|}
\hline \multirow[b]{2}{*}{ Variables and categories } & \multicolumn{2}{|c|}{ Change of club engagement $\mathrm{W}_{\mathrm{I}}-\mathrm{W}_{2}$} \\
\hline & $\begin{array}{c}\text { Engagement } \\
\text { decreased }\end{array}$ & $\begin{array}{l}\text { Engagement } \\
\text { increased }\end{array}$ \\
\hline & \multicolumn{2}{|c|}{ Relative risk } \\
\hline Engagement at Wave I (baseline) & $2.4^{* * * *}$ & $0.66^{* * * *}$ \\
\hline \multicolumn{3}{|l|}{ Gender: } \\
\hline Male & I.00 & I.OO \\
\hline Female & 0.97 & I.02 \\
\hline Age in years & I.OO & I.oO \\
\hline \multicolumn{3}{|l|}{ Change in economic activity $\mathrm{W}_{\mathrm{I}}-\mathrm{W}_{2}$ : } \\
\hline Working both waves & I.OO & I.OO \\
\hline Not working both waves & $0.74^{* *}$ & I.02 \\
\hline Not working to working & 0.66 & I.09 \\
\hline Working to retired & 0.98 & I.07 \\
\hline Working to unemployed & $\mathrm{I} .5 \mathrm{I}$ & I.6I \\
\hline Working to sick/disabled & 0.75 & 0.84 \\
\hline Working to looking after home & $0.5^{8}$ & I. 33 \\
\hline Degree of self-reported health problems at $\mathrm{W}_{\mathrm{I}}$ & I.IO* & $0.90^{* *}$ \\
\hline Change in self-reported health ${ }^{1}$ & 0.94 & $\mathrm{I} . \mathrm{I} 2^{* *}$ \\
\hline \multicolumn{3}{|l|}{ Partner: } \\
\hline Married or cohabiting & I.0O & I.OO \\
\hline Lives without a partner & 0.92 & I.II \\
\hline Household wealth (quintiles) & 0.99 & เ.o6* \\
\hline \multicolumn{3}{|l|}{ Occupational class (NS-SEC): } \\
\hline Routine and manual & I.OO & I.00 \\
\hline Intermediate & 0.88 & I.09 \\
\hline Managerial or professional & $0.77^{* *}$ & I. $29^{* *}$ \\
\hline \multicolumn{3}{|l|}{ Educational qualification: } \\
\hline No qualification & $\mathrm{I} .00$ & I. .00 \\
\hline NVQI-3, CSE, GCE-O, GCE-A, foreign/others & $0.83^{*}$ & I.I7 \\
\hline $\mathrm{NVQ}_{4}-5$, degree, higher & $0.68 * * *$ & I. 23 \\
\hline
\end{tabular}

Notes: Sample size 6,640 . Pseudo $R^{2}=$ o.I2. I. For change by a single (ordinal) category during $\mathrm{W}_{\mathrm{I}}$ to W2. CSE: Certificate of Secondary Education. GCE-A: General Certificate of Education Advanced Level. GCE-O: GCE Ordinary Level. NS-SEC: Office of National Statistics Socio-economic Classification. NVQ: National Vocational Qualification.

Significance levels: $* p<0.05,{ }^{* *} p<0.01,{ }^{* * *} p<0.00 \mathrm{I}$.

such stratified models. Nonetheless, our attempts to model this have indicated that the effects of retirement might differ slightly by socio-economic subgroup; for instance, in the stratified cross-sectional models, health problems did not lower cultural participation in the highest wealth quintile, but they did for the other quintiles. For membership in clubs, the retired respondents of highest education engaged more than their still working counterparts, which again was not the case for middle and lower educational classes. Similar differences were shown in the stratified models

\section{CAMBRIDGE JOURNALS}


over two waves. As indicated above, retiring between the two waves did not change cultural participation significantly, but in the stratified model retirement had a negative effect for the lowest occupational class, but not the others. Concerning club membership, health problems appeared to be without consequence among the highest educational class. All these effects are based on small numbers, but are nonetheless worth further exploration even if it was only the absence of negative effects of health in higher classes that led to amplified social inequalities.

\section{Discussion and conclusion}

The cross-sectional analysis of English Longitudinal Study of Ageing data has shown that education, occupational class and wealth play a key role for each of the three observed leisure activities, and that this applied most to participation in cultural activities (visiting or attending museums/ galleries, theatres/concerts/the opera, and the cinema). Educational attainment was clearly the strongest marker of activity and partly explained the age differences. Being a non-working retired person increased only the probability of having a hobby - in other respects, and after controlling for health and socio-economic status, retirees were no different from working and non-retired persons. Respondents who said that they were retired but still working were also more likely to have a hobby, and they participated significantly more in cultural activities. This underlines that many of this (small) group were in a rather privileged position. By contrast, being not retired and not working lowered the extent of cultural participation, an effect that was driven mainly by those who were permanently ill or disabled and that operated over and above the direct effect of health.

Not being married or cohabiting, that is living without a partner, associated with increased cultural participation and club engagement, but did not affect having a hobby. So, (not) having a partner arguably affected activities pursued out of the home. Put differently, married or cohabiting people who wanted to participate in activities with others did not need to leave their homes as much as people who lived alone, an association that points to the social function of cultural participation and club engagement. In spite of controlling for socio-economic position and retirement effects, there were still small but significant cross-sectional age differences. The very oldest were less engaged than the youngest, and in the case of cultural participation, the very youngest were more active than all other age groups, whereas having a hobby and being engaged in clubs attained the highest prevalence among those aged $55^{-5} 59$ and 6o-75 years, respectively. 
Explanations for the observed age differences other than simple age or lifecourse effects must be considered even though they are difficult to address empirically. Research on leisure has discussed changes in both the structural characteristics of leisure and in its meaning. The amount of spare time and money available for other than basic needs has increased across the population (Cutler and Hendricks I990: 178). This goes with a change of values, which has been depicted in different ways. For example, it has been claimed that individual self-development and freedom (in all aspects of life) have become more important, while the fulfilment of duties has become less significant (e.g. Bickel, Lalive d'Épinay and Vollenwyder 2005; Buchmann and Eisner 1997; Cutler and Hendricks 1990: 172; Inglehart 1971, 1990). Gilleard et al. (2005) saw the ageing of the cohorts that were socialised in their youth into the ig6os consumer culture as one factor that accounted for the emergence of the Third Age ( $c f$. Gilleard and Higgs 2005, 2007). The extension and diversification of leisure cultures has been well demonstrated, although interpreted in different ways. Age differences can result from the fact that different cohorts have experienced different leisure cultures in their youth and early adulthood. This cannot be reduced to their different socio-economic background (Cutler and Hendricks 1990: I72), but is connected to it. Even if the change in the cultures of leisure is slow and gradual, the experiences of the oldest and the youngest cohorts in this investigation are very likely to differ because they were born more than 30 years apart.

The changes in participation observed over the two waves of ELSA have clearly been influenced by the socio-economic positions of the respondents, with those of higher educational and occupational backgrounds being more likely to have intensified their activities, or to have explored new ones, and the lower classes more likely to have decreased their activities. As in the cross-sectional analysis, education was the key factor among the socio-economic dimensions, while occupational class was less important and wealth only occasionally significant. However, none of these relations between socio-economic position and change in activity were very strong. An augmentation of socio-economic differences was observed over the two years, which points to growing inequalities with age, although we must be cautious when generalising the result. If we assume that the underlying causal processes continue over time, the socioeconomic 'gap' in these activities will increase. It has been shown that inequalities grow slightly with age, but no evidence suggested that retirement from work is a crucial turning point when inequalities deepen. There was little indication that those who had recently retired were more engaged in clubs or cultural activities than before, although picking up a hobby was more frequent amongst recent retirees. The interpretation of 
engagement in clubs has to be handled with care, however, because the ELSA question asked about attendance at committee meetings during the previous year. People who stopped working could have done so only in the last two months so that the temporal relation of the two - for example retirement and increase or decrease of engagement-remains unclear. Notwithstanding a change of engagement could still be related to retirement even if the latter happens later, for example as a planned withdrawal in the prospect of retirement.

When work was given up under the unfavourable circumstances of illness or disability, there was an additional negative effect over and above the health problems themselves, and a similar effect was present for the other examined leisure activities. This relationship requires further investigation, for example by differentiating disabilities from chronic illness. In spite of this, the underlying logic of social inequalities after retirement and in old age did not seem to differ from that during younger and working life. In general, health strongly affected activities before and after retirement. Living alone increased the chances that the respondent's engagement in cultural activities became more intense, again indicating the social dimension of activities that take place outside the home, but this did not apply to having a hobby and engagement in clubs.

This investigation has confirmed the general picture from previous studies of continuity in leisure activities but has also enabled useful differentiations. In previous research, neither of the alternative hypotheses, of a radical change of leisure behaviour after retirement, or of absolute continuity, has been supported. In general, and independently from retirement, activities outside the home and those that require physical activity decreased with age. Some studies have reported gains in activities or new interests after retirement, but they refer only to activities at home, solitary activities and walks (Bickel, Lalive d'Épinay and Vollenwyder 2005: I48; Cribier I979: 413-5; Cutler and Hendricks I990: I73; Long I987; Stebbins 2000: I5; see also Lee 2005; Nimrod 2007; Nimrod, Janke and Kleiber 2009; Rosenkoetter, Garris and Engdahl 200I). For most contexts and all other activities, continuity prevailed. Only if retirement was under conditions of bad health did leisure activities decline - but in these cases, health seemed to be the reason for both retirement and reduced (outdoor) leisure activities, rather than the other way round ( $c f$. Long I987: 66; Stebbins 2000). Concerning the underlying social inequalities, the dominant pattern was again continuity. With regard to physical and manual activities, a reduction of inequalities was found ( $c f$. Attias-Donfut I986; Bickel, Lalive d'Épinay and Vollenwyder 2005).

The higher probability of having a hobby after retirement could be associated with changing time budgets and indirectly confirms evidence 
from other studies that it is home activities that are positively influenced by retirement (either through intensification of activities or taking up a new hobby). Engagement in clubs was highest around the time of retirement but no direct effect of retirement was found. Apart from the changing time budgets after retirement, increased engagement may constitute a kind of individual preparation for labour-force exit, or was connected to a partial withdrawal from the labour market. Linked to age, but not to be conflated with it, are life course effects other than retirement; for instance, in many cases the last children might have left the home when their parents were aged in the mid-fifties, leaving them more time to develop new interests or to extend existing ones, like collaboration in club committees. Some leisure effects of retirement might also be very short term. As there were no observations during the two years between the two ELSA waves, such a potential 'honeymoon' period of leisure activities would not appear in the data.

Future waves of ELSA might give a more complete picture of the shifts connected to work status changes. They will also allow for a better distinction between age and cohort effects - the interpretation of the (crosssectional) differences between age groups is not straightforward. Certain cohorts could have been more socialised into collective engagement. Controlling for education and occupational class did (at least) reduce the age effects considerably, as did controlling for health. This suggests that at least part of the age differences can be explained by the different educational and occupational backgrounds of the cohorts. Although health was also closely connected to individual ageing, an additional cohort effect is plausible, namely that cohorts born earlier in the 2oth century had worse 'baseline' health than those born later, because they grew up under tougher circumstances and because of their lower educational and occupational status. We need to know if the younger ELSA respondents, who are better educated and display better health than the cohorts born earlier, continue their more active lifestyle into older ages. This will be the real test of persistent change across cohorts and of the diffusion of a more active 'Third Age'.

It should also be noted that this paper has not sufficiently taken into account the difference between old age and advanced old age. Most outof-home activities show a clear decrease around the age of 80 years when health-related problems become widespread. Some of the literature suggests that it is at this age that inequalities reduce, after increasing from early adulthood. These processes should also be observable in the ELSA sample as the study progresses. The comparison between the different types of activities studied here shows that it is necessary to differentiate further between fields of leisure activity. There are clearly people who try 
new activities in retirement, but these are rarely highbrow activities such as going to classical music concerts. A more precise definition of what constitutes a 'hobby or pastime' and a closer assessment of home activities are required, over and above the usual evidence on the high number of hours that older people watch television. Furthermore, the relation between different activities should be explored in detail. Another neglected aspect has been social relations, which we captured only partially and indirectly with the variable for whether the respondent lived with a partner. Whether activities are pursued alone or with other people and how this influenced change with age and retirement requires further exploration, including possible interactions with gender and class. All these issues are connected to the question of what these different activities mean to the respondents, which would require complementary qualitative studies.

To complete the picture of the processes connected to retirement and ageing, the subjective meanings of all activities, including paid work, must be investigated in more detail, as Long (I987) and Attias-Donfut (1986: 389) began. This should also include the meanings and values attached to paid work before retirement. Besides, the effects of leisure culture on retirement and its timing have to be taken into account ( $c f$. Colley I985). As the presented evidence is particular to England, the effect of the liberal United Kingdom welfare regime on the retirement transition, on retirement and on inequality structures in old age could not be discussed systematically here. Whether the finding of a prevailing continuity of inequality structures, as they appear in leisure activities, would be the same in different welfare regimes, remains to be investigated.

The Third Age as imagined by Laslett (I987, I996/I989), a time of new activities and self-development, has not become reality, notwithstanding that the prospects of a continuing active lifestyle after retirement seem to be good for most retirees, and that some privileged groups come close to Laslett's vision. Surprisingly, some of these active retirees continue to do paid work. Maybe they represent the cultural model of the Third Age in its purest form. Still, the information on this very small group and on the role (paid) work plays in their life is insufficient to draw this conclusion - not all of them enjoyed above-average socio-economic status. Whether such very active leisure patterns of retirement will expand across the older population in the future depends very much on the educational, financial and other resources of future retirees. Today's pensioners have benefited from a very favourable combination of long and stable working lives in times of economic growth, which may not be easily repeated. All of this should encourage, rather than discourage, further research on leisure and the cultural dimensions of later life. 


\section{Acknowledgements}

The authors are grateful to the UK Economic and Social Research Council, whose funding of the project 'Inequalities in Health in an Ageing Population: Patterns, Causes and Consequences' (RES-ooo-23-0590) supported the work on this paper. The ELSA data were made available through the UK Data Archive. ELSA was developed by a team of researchers based at University College London, the Institute for Fiscal Studies, and the National Centre for Social Research. The funding for ELSA is provided by the National Institute of Aging in the United States, and a consortium of UK Government departments co-ordinated by the Office for National Statistics. The developers and funders of ELSA and the Archive do not bear any responsibility for the analyses or interpretations presented here.

\section{NOTES}

I From a different and less critical theoretical background, and without the emphasis on retirement and welfare policy, the theory of age stratification (Riley, Johnson and Foner 1972) also identified age as one of the most important dimensions of inequality.

2 It should be borne in mind that Laslett's concept of the third age is explicitly concerned to promote an optimistic normative agenda, aimed at culturally adjusting society to recent demographic changes. He wrote, 'the theory of the Third Age has to be doctrine as well as structural analysis' (Laslett I996/I989: 202).

3 A precise definition of 'leisure' is elusive, because the meaning changes across the lifecourse. Here we apply a broad and somewhat residual definition of leisure as 'time free from the necessity of maintaining oneself and one's dependents' (Cutler and Hendricks 1990: 172; for further discussion see Stebbins 2000: $5^{-6}$ ).

4 Nonetheless, it is still necessary to differentiate by pension system and welfare system.

5 For earlier life the same can be assumed, mainly mediated by the status of one's parents.

6 Another group which may multiply are those who lose (parts of) their (private) pension because of financial mismanagement or stock-market crashes. This is most likely in more liberal and privatised pension systems, and the affected persons are more prone to a real decrease in leisure participation.

7 The exact wording, repeated for the three activities, was: 'How often, if at all, do you do any of the following activities?' There was a similar question on the frequency of eating out in restaurants, but this activity was related to the others only weakly and would have lowered the reliability of the index in an unacceptable way.

8 At first glance, the good fit of cinema visits into the index is surprising because cinema seems to belong more to a pattern of popular culture than the two other activities, but this is less likely to apply to the older members of the ELSA sample.

9 This list included political parties/trades unions/environmental groups, tenants groups/resident groups/neighbourhood watch, church/other religious groups, charitable associations, education/arts/music groups, evening classes, social clubs, sports clubs/gyms/exercise classes and any other organisations/clubs/societies. The respondent was able to tick several categories of clubs.

Io Especially for older people, it makes sense to use wealth instead of income as the indicator of the financial situation of a household - after retirement there is often a 
decrease in substantial income which is in some cases compensated by 'dis-saving' (for a more detailed discussion see Crown 2001 : $363^{-6}$ ).

I I Because of missing values in the independent variables, this number is reduced in the descriptive and multivariate analyses.

I2 These models are similar to proportional odds models (ordinal logistic regressions), but the assumption of proportional odds (parallel regressions) is released for some (not all) variables. The decision on which variables the assumption has to be released has been taken with the help of the 'Autofit' procedure of the 'Gologit2' command in STATA. For the details of this command and the statistical basis see Williams (2006).

I3 The relative risk is a ratio of the probability of having a hobby in the respective category versus the same probability in the reference category. It is not the same as the odds ratio given in simple (binary) logistic regressions: this is the factor by which the odds of the 'event' change under influence of the respective category and relative to the reference category, the odds being the ratio of the chances of occurrence and the chances of non-occurrence $(\mathrm{p} / \mathrm{I}-p)$.

I4 When detailed age groups were used in the same model, none were significant.

\section{References}

Atchley, R. C. 1989. A continuity theory of normal aging. The Gerontologist, 29, 2, I83-90.

Attias-Donfut, C. I986. Les nouveaux retraités: un groupe social novateur? [The new retirees: an innovator social group?] Loisir et Société/Society and Leisure, 9, 2, 377-40I.

Banks, J., Karlsen, S. and Oldfield, Z. 2003. Socio-economic position. In Marmot, M., Banks, J., Blundell, R., Lessof, C. and Nazroo, J. (eds), Health, Wealth and Lifestyles of the Older Population in England: The 2002 English Longitudinal Study of Ageing. Institute for Fiscal Studies, London, $7 \mathrm{I}-\mathrm{I} 25$.

Banks, J., Breeze, E., Lessof, C. and Nazroo, J. (eds) 2006. Retirement, Health and Relationships of the Older Population in England: The 2004 English Longitudinal Study of Ageing (Wave 2). Institute for Fiscal Studies, London.

Banks, J., Breeze, E., Lessof, C. and Nazroo, J. 2008. Living in the 2Ist Century: Older People in England. The 2006 English Longitudinal Study of Ageing (Wave 3). Institute for Fiscal Studies, London.

Bardasi, E., Jenkins, S. P. and Rigg, J. A. 200o. Retirement and the Economic Well-being of the Elderly: A British Perspective. ISER Working Paper 2000-33, Institute for Social and Economic Research, University of Essex, Colchester, UK.

Bennett, T. and Silva, E. B. (eds) 2006 a. Culture, Tastes and Social Divisions in Contemporary Britain. Cultural Trends, I5, 2/3, 85-246.

Bennett, T. and Silva, E. B. $2006 \mathrm{~b}$. Introduction. Cultural capital and inequality: policy issues and contexts. In Bennett, T. and Silva, E. B. (eds), Culture, Tastes and Social Divisions in Contemporary Britain. Cultural Trends, I5, 2/3, 87-106.

Bennett, T., Savage, M., Silva, E. B., Warde, A., Gayo-Cal, M. and Wright, D. 2008. Culture, Class, Distinction. Routledge, London.

Bickel, J.-F., Lalive d'Épinay, C. and Vollenwyder, N. 2005. Changement et continuité dans les loisirs: une comparaison de cohortes [Change and continuity in leisure: a cohort comparison]. L'Année Sociologique, 55, I, I29-70.

Blane, D. 2006. The life course, the social gradient, and health. In Marmot, M. and Wilkinson, R. G. (eds), Social Determinants of Health. Oxford University Press, Oxford, $54-77$.

Buchmann, M. and Eisner, M. 1997. The transition from the utilitarian to the expressive self: 1900-I992. Poetics, 25, 2/3, I57-75. 
Chan, T. W. and Goldthorpe, J. H. 2005. The social stratification of theatre, dance and cinema attendance. Cultural Trends, 1 4, 3, 193-212.

Chan, T. W. and Goldthorpe, J. H. $2007 a$. Social stratification and cultural consumption: music in England. European Sociological Review, 23, I, I-I9.

Chan, T. W. and Goldthorpe, J. H. 2007 b. Social stratification and cultural consumption: the visual arts in England. Poetics, 35, 2/3, 67-214.

Colley, L. 1985. Work occupation and leisure patterns of self-supporting women in preand post-retirement. Loisir et Société/Society and Leisure, 8, 2, 63I-58.

Cribier, F. 1979. Les vacances à l'heure de la retraite: conduites d'âge, conduites de génération [Holiday travel in retirement: age patterns and generational patterns in behaviour]. Loisir et Société/Society and Leisure, 2, 2, 399-426.

Crown, W. 200I. Economic status of the elderly. In Binstock, R. H. and George, L. K. (eds), Handbook of Ageing and the Social Sciences. Academic, San Diego, California, 352-68.

Cumming, E. and Henry, W. E. 196r. Growing Old: The Process of Disengagement. Basic, New York.

Cutler, S. J. and Hendricks, J. I990. Leisure and time use across the life course. In Binstock, R. H. and George, L. K. (eds), Handbook of Aging and the Social Sciences. Academic, New York, I69-85.

Ferraro, K. J. 200 . Aging and role transitions. In Binstock, R. H. and George, L. K. (eds), Handbook of Ageing and the Social Sciences. Academic, San Diego, California, 313-30.

George, L. K. 200I. The social psychology of health. In Binstock, R. H. and George, L. K. (eds), Handbook of Ageing and the Social Sciences. Academic, San Diego, California, 217-33.

Gilleard, C. and Higgs, P. 200o. Cultures of Ageing. Self, Citizen and the Body. Prentice Hall/ Pearson Education, Harlow, UK.

Gilleard, C. and Higgs, P. 2005. Contexts of Ageing. Class, Cohort and Community. Polity, Cambridge.

Gilleard, C. and Higgs, P. 2007. The third age and the baby boomers: two approaches to the social structuring of later life. International Journal of Aging and Later Life, 2, 2, 13-30.

Gilleard, C., Higgs, P., Hyde, M., Wiggins, R. and Blane, D. 2005. Class, cohort, and consumption: the British experience of the Third Age. Journal of Gerontology: Social Sciences, $6 \mathbf{0 B}, 6, \mathrm{~S}_{305}-\mathrm{Io}$.

Ginn, J. and Arber, S. I99. Gender, class and income inequalities in later life. British Fournal of Sociology, 42, 3, 369-96.

Havighurst, R. J. I957. The leisure activities of the middle-aged. American Fournal of Sociology, 63, 2, I52-62.

Havighurst, R. J., Neugarten, B. L. and Tobin, S. S. I968. Disengagement and patterns of aging. In Neugarten, B. L. (ed.), Middle Age and Aging: A Reader in Social Psychology. University of Chicago Press, Chicago, I6I-72.

Havighurst, R. J., Munnichs, J. M. A., Neugarten, B. L. and Thomae, H. (eds) rg69. Adjustment to Retirement: A Cross-national Study. Van Gorcum, Assen, The Netherlands.

Herd, P. 2006. Do functional health inequalities decrease in old age? Educational

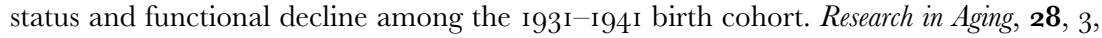
$375-92$.

House, J. S., Kessler, R. C., Herzog, A. R., Mero, R. P., Kinney, A. M. and Breslow, M. J. I992. Social stratification, age, and health. In Schaie, K. W., Blazer, D. and House, J. S. (eds), Aging, Health Behaviors, and Health Outcomes. Lawrence Erlbaum, Hillsdale, New Jersey, $\mathrm{I}^{-} 32$.

House, J. S., Lepkowski, J. M., Kinney, A. M., Mero, R. P., Kessler, R. C. and Herzog, R. A. I994. The social stratification of aging and health. Fournal of Health and Social Behavior, 35, 3, 213-34.

Inglehart, R. 197I. The silent revolution in Europe: intergenerational change in postindustrial societies. American Political Science Review, 65, 4, 991-IoI7. 
Inglehart, R. I99o. Culture Shift in Advanced Industrial Society. Princeton University Press, Princeton, New Jersey.

Kohli, M. 1990. Das Alter als Herausforderung an die Theorie sozialer Ungleichheit [Old age as a challenge for the theory of social inequality]. In Berger, P. A. and Hradil, S. (eds), Lebenslagen, Lebensläufe, Lebensstile [Life Situations, Life Courses, Life Styles]. Soziale Welt, special issue 7, Schwartz, Göttingen, Germany, 387-406.

Kohli, M., Künemund, H., Motel, A. and Szydlik, M. I999. Familiale Generationenbeziehungen im Wohlfahrtsstaat: Die Bedeutung privater intergenerationeller Hilfeleistungen und Transfers [Family relations in the welfare state: the significance of intergenerational assistance and transfers]. WSI-Mitteilungen, 52, I, 20-5.

Laslett, P. 1987. The emergence of the Third Age. Ageing \& Society, 7, 2, 133-6o.

Laslett, P. 1996/1989. A Fresh Map of Life: The Emergence of the Third Age. Macmillan, Basingstoke, UK.

Lee, M. K. 2005. Pre- and post-retirement leisure in South Korea and the implications for life satisfaction. World Leisure Fournal, 47, 4, 23-31.

Long, J. 1987. Continuity as a basis for change: leisure and male retirement. Leisure Studies, 6, I, 55-70.

Marmot, M., Siegrist, J. and Theorell, T. 2006. Health and the psychosocial environment at work. In Marmot, M. and Wilkinson, R. G. (eds), Social Determinants of Health. Oxford University Press, Oxford, 97-130.

Marmot, M., Banks, J., Blundell, R., Lessof, C. and Nazroo, J. (eds) 2003. Health, Wealth and Lifestyles of the Older Population in England: The 2002 English Longitudinal Study of Ageing. Institute for Fiscal Studies, London.

McGoldrick, A. E. I989. Stress, early retirement and health. In Markides, K. S. and Cooper, C. L. (eds), Aging, Stress and Health. Wiley, Chichester, UK, 9I-I I8.

Nimrod, G. 2007. Expanding, reducing, concentrating and diffusing: post-retirement leisure behavior and life satisfaction. Leisure Sciences, 29, I, I9I-2I I.

Nimrod, G., Janke, M. and Kleiber, D. 2009. Expanding, reducing, concentrating and diffusing: activity patterns of recent retirees in the United States. Leisure Sciences, 31, I, $37-52$.

O'Rand, A. 200I. Stratification and the life course: the forms of life-course capital and their interrelationships. In Binstock, R. H. and George, L. K. (eds), Handbook of Ageing and the Social Sciences. Academic, San Diego, California, I97-2I3.

Parker, S. 197I. The Future of Work and Leisure. MacGibbon and Kee, London.

Parker, S. I979. Retirement - leisure or not? Loisir et Société/Society and Leisure, 2, 2, 329-40.

Parker, S. I982. Work and Retirement. George Allen and Unwin, London.

Phillipson, C. I982. Capitalism and the Construction of Old Age. Macmillan, London.

Phillipson, C. 1998. Reconstructing Old Age: New Agendas in Social Theory and Practice. Sage, London.

Riley, M. W., Johnson, M. and Foner, A. (eds) 1972. Aging and Society. Volume 3, A Sociology of Age Stratification. Russell Sage Foundation, New York.

Rosenkoetter, M. M., Garris, J. M. and Engdahl, R. A. 200I. Postretirement use of time: implications for preretirement planning and postretirement management. Activities, Adaptation and Ageing, 25, 3, I-I8.

Stebbins, R. A. 2000. The extraprofessional life: leisure, retirement and unemployment. Current Sociology, 48, I, I-I8.

Townsend, P. I98I. The structured dependency of the elderly: a creation of social policy in the twentieth century. Ageing $\mathcal{E}^{\circ}$ Society, I, I, 5-28.

Townsend, P. 2006. Policies for the aged in the 2ist century: more 'structured dependency' or the realisation of human rights? Ageing $\mathcal{E}$ Society, 26, 2, I6I-79.

Walker, A. I980. The social creation of poverty and dependency in old age. Fournal of Social Policy, 9, I, 49-75. 
I72 Simone Scherger et al.

Weiss, R. and Bass, S. 2002. Introduction. In Weiss, R. and Bass, S. (eds), Challenges of the Third Age. Oxford University Press, Oxford, 3-12.

Williams, R. 2006. Generalized ordered logit/partial proportional odds model for ordinal dependent variables. Stata Fournal, 6, I, 58-82.

Accepted 24 May 20Io; first published online I8 October 2010

Address for correspondence:

Simone Scherger, Centre for Social Policy Research (Zes),

University of Bremen, Barkhof, Parkallee 39, 28209 Bremen, Germany.

E-mail: simone.scherger@zes.uni-bremen.de 